Peer review: This article has been subject to a double blind peer review process

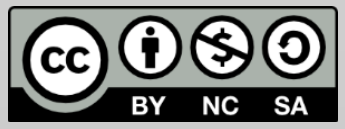

(C) Copyright: The Authors. This article is issued under the terms of the Creative Commons Attribution NonCommercial Share Alike License, which permits use and redistribution of the work provided that the original author and source are credited, the work is not used for commercial purposes and that any derivative works are made available under the same license terms.

\section{Teaching Synaesthesia as a Gateway to Creativity}

\author{
Monica D. Murgia* \\ *Correspondence: murgia7@gmail.com
}

\begin{abstract}
This article encapsulates my experience of teaching creativity within a higher education curriculum. Creativity often eludes common understanding because it involves using different conceptual streams of thought, often times developing unconsciously and manifesting in the prized "eureka" moment. In 2009, I began explaining the neurological condition of synaesthesia and later introduced this phenomenology in a course designed to cultivate creativity to first year fashion design students. There are many challenges in teaching creativity. Through teaching this course, I discovered that the first challenge is making the students conscious of their own qualitative beliefs on creativity and art. The second is creating exercises to challenge and alter these beliefs, thus forming a new way of thinking and experiencing the world. The most resistance from my students arose when experimenting with nonrepresentational art. They did not have a conscious framework for making and evaluating abstract art. Introducing synaesthesia, a neurologically-based condition that "merges" two or more sensory pathways in the brain, gave my students a framework for discovery. Understanding sensory modalities and ways in which these modalities can blended together in synaesthesia proved to be a gateway to creativity in many of my students. The scope of this article chronicles how I developed my teaching methodology, the results it created in my classroom, as well as its effects on my own artistic practice.
\end{abstract}

Keywords: synaesthesia; creativity; arts practice; teaching; cross-modal

\section{Introduction}

The great enigma in fashion and art lies around creativity: Where does it come from? Is it innate in some people, and missing in others? Is it something that can be fostered, and if so, how? I am a firm believer that creativity, however elusive and indefinable, is something that can be taught. In fact, there are many things that have to be "unlearned" to allow creativity to grow. The visual experience is whitewashed with 
memories, thoughts, and ideas of what should be present, instead of what is actually there.

In The Creative Mind: Myths and Mechanisms, Margaret A. Boden shares a similar view. She explains that creativity is rooted in everyday abilities such as conceptual thinking, perception, and memory. Therefore, to some degree everyone is creative. Boden explains that there are three different types of creativity: the first involves making unfamiliar combination of familiar ideas; the second is exploration of conceptual spaces; and the third is transformation of conceptual spaces (Boden, 2004: 3-4). What makes some people more creative, then, is their ability to explore and transform their own ideas and mental processes.

In 2010, I began teaching a college course, entitled Fashion Seminar. This course was for first year fashion design students, and aimed to help them develop an identity as a designer and stimulate creativity within the design discipline. A large component of the class involved developing an art portfolio. The portfolio was comprised of exercises that encouraged the student develop creative and abstract thinking skills. Each student was required to select a natural and manmade image as inspiration. The goal of each weekly portfolio assignment was to challenge the students to see these images in new ways. By repeatedly looking at the same images, the portfolio exercises challenged the students to take something familiar and examine it different exercises, perspectives, and reinterpret it with various media. Each week, an assignment was presented to challenge the students to adjust their visual perceptions in order to encourage their creativity.

I taught this course for a year and a half, with as many as 5 separate sections of the same course in a term. Over a number of terms of teaching this course, the most successful assignment, in terms of the creative output it generated, was called "multiple sensory". As the title suggests, the student has to take an inspirational image and create a visual representation of a multi-sensory experience evoked by that image. The learning outcome was aimed at encouraging the students to experiment with nonrepresentational, or abstract, art. In abstract art, the selection of media and colour combinations is more important than a recognizable image. This type of art creates a visceral reaction within the viewer. Many of my students had no previous experience creating abstract art, so this exercise served as a gateway to experiment with it. To properly communicate the idea of representing multi-sensory experience, I developed a curriculum that included case studies from neuroscience. In particular, I discussed the phenomenon of synaesthesia, a neurological condition, to help students develop new methods of creating art. Introducing and describing synaesthsia in the classroom 
gave the students a structure for experimenting with abstract art. Over time, they formed new was for observing, creating, and evaluating nonrepresentational forms For example, one student, 'Monet B', took the inspirational image of a woman smoking. 'Monet $B$ ' then created a series of small paintings that expressed a visual representation of the smell and taste of smoking.

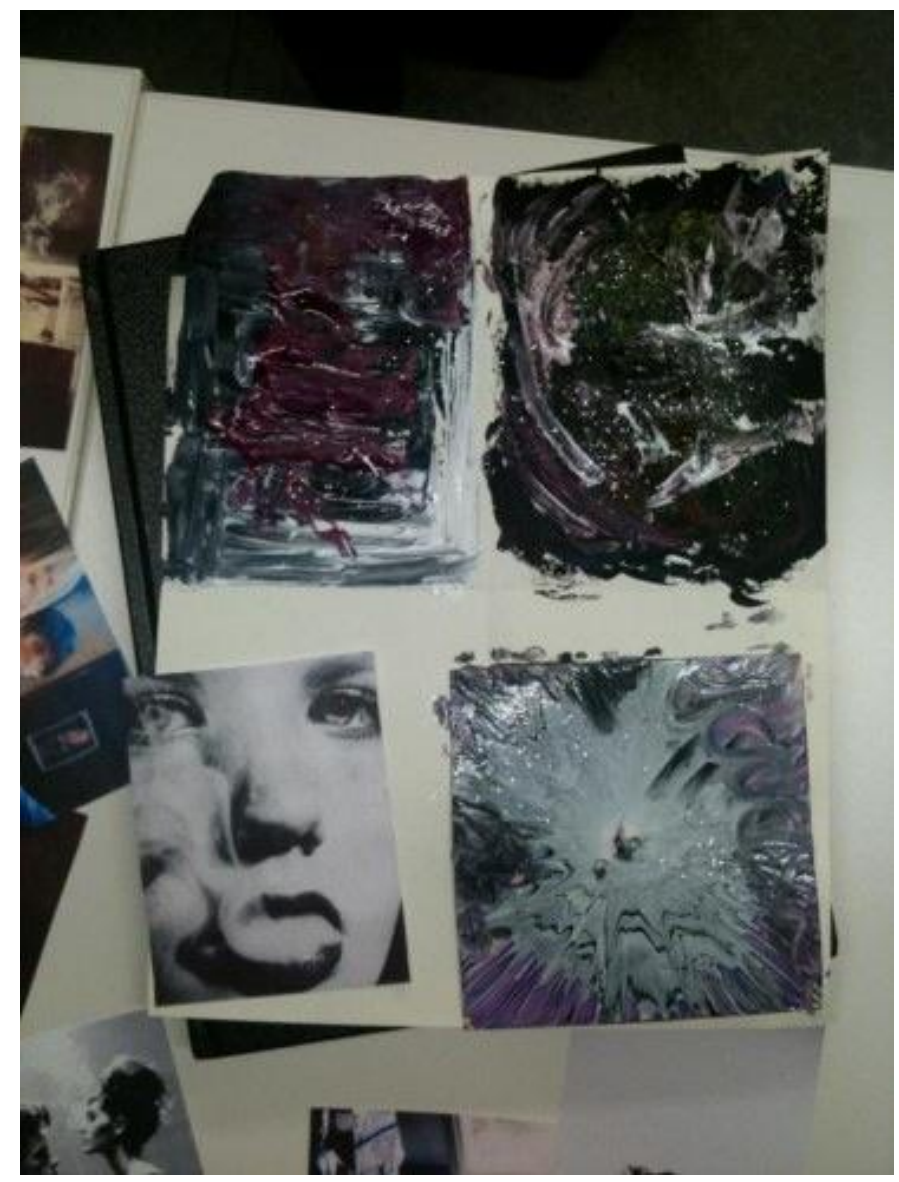

\section{Phenomenology of Synaesthesia}

Synaesthesia is a neurologically-based condition in which stimulation of one sensory pathway (e.g. visual pathway) leads to automatic, involuntary experiences in a second sensory pathway (e.g. aural pathway). This means that two or more senses merge together instead of remaining separate. For instance, some synaesthetes-those that have synaesthesia- will see colours when they hear sound or touch objects.

Every case of synaesthesia is different. Some people see colours while tasting food. Others hear sounds from the smell of fragrances. Some can taste sounds and images. There are more than 100 different types of synaesthesia. The most commonly reported phenomenon is coloured hearing, that is, sounds producing a visual manifestation. Seeing letters 
or numbers in colours is also widely reported. Each letter or number has a corresponding colour.

The early researchers of synaesthesia were Heinrich Kluver (1897-1979) and Georg Anschutz (1886-1953), both of whom worked independently. Frustrated by romanticized, poetic, and vague descriptions of what synaesthetes were experiencing, they conducted rigorous studies with the collaboration of synaesthetes to peer inside their minds, and produce a classification of the experience. These studies included asking the synaesthetes to create works of art as a way of capturing their subjective experience.

Synaesthesia became a romantic ideal in literature, but was widely regarded as an imaginary condition, or a drug-induced hallucination. However, the advent of modern medicine affirmed that synaesthesia is a real neurological condition. Dr. Vilayanur S. Ramachandran and Dr. Edward M. Hubbard have pioneered research and education on synaesthesia, demonstrating through their clinical experiments that synaesthetes experience a cross wiring of different sensory-processing regions in the brain (Ramachandran and Hubbard, 2003: 54). In fact, they have produced evidence of this cross wiring of the sensory pathways in the colourblind: 'We also observed one case in which we believe cross activation enables a colourblind synaesthete to see numbers tinged with hues he otherwise cannot perceive; charmingly, he refers to these as "Martian colours"' (Ramachandran and Hubbard, 2003: 57).

It is difficult to say how many people have synaesthesia. First of all, those that experience this blending of the senses since birth do not see it as a "condition". This is their regular way of living. Therefore, synaesthetes do not understand that other people have different sensory experiences. Secondly, while research has been conducted on synaesthesia since the 1880 s, findings have not been widely distributed. It has been estimated that as many as 1 per every 100 people experiences synaesthesia. After one of my workshops, a student approached me and said that he experienced the exact phenomenon I explained. Sean let me briefly interview him. The full recording is available here https://www.youtube.com/watch?v=U54FYiTR2pl, in which he explains:

"When I hear music it's like an instant graphic. . . I thought it was normal. Music is a constant inspiration for me, because it's like an instant installation in my mind."

To a certain degree, everyone experiences synaesthesia; Stroop interference tests are perfect illustrations (De Young, 2014). Stroop interference tests use the words to describe a colour but are written in a different coloured ink. For example, the word blue is printed in red ink. 
You are asked to identify the word, and ignore the colour - which after a succession of coloured words becomes tricky to instantaneously identify the word. The mind starts to associate more quickly with the colour of the text, instead of the meaning of the text. According to a scientific study, synaesthesia is seven times more common in creative people than in the general population (Ramachandran and Hubbard, 2003: 57).

\section{Teaching Methodology - Synaesthesia in the Classroom}

During my research of the various types of synaesthesia, I discovered that they each contained a common thread. Synaesthesia allows the individual to make arbitrary links between seemingly unrelated visceral stimuli. This ability to successfully link apparently unrelated ideas and concepts is the first of Boden's creative triad.

To access exploratory and transformative creativity, Boden explains that one must have a structure. Creativity is "not a matter of abandoning all the rules, but of changing the existing rules to create a new conceptual space. Constraints on thinking do not merely constrain, but also make certain thoughts - certain mental structures - possible" (Boden, 2004: 58). Synaesthesia became the structure and conceptual space for this particular assignment. In addition to explaining the neurological phenomenon of synaesthesia, I showed examples of relevant artwork to my students to demonstrate the creative potential of the synaesthetic experience. Through my own research, I found evidence of many painters that exhibited synaesthetic characteristics. For instance, the exhibition catalog for the show Synaesthesia: Art and the Mind, a show produced by McMaster Museum of Art, examined the work of legendary synaesthete artists, including Vincent Van Gogh, Wassily Kandinsky, Charles Burchfield, Joan Mitchell, and Duke Ellington.Beyond the subject matter, all of the art by the aforementioned painters includes unusual colour combinations, rhythmic use of lines and shapes, and parts of the composition enveloped in auras of colour. These are typical signatures of a synaesthetic artist.

In my teaching, I was careful to select vivid and impactful works of art, and describe their compositions. I would ask the students to look at the art carefully. What other visceral reactions were induced in the scribbles, scratches, and drips of paint in front of them? Slowly, they started to make the association between visual imagery and other sensory reactions. Perhaps that dripping red paint on one of Joan Mitchell's canvases was the murky sense of walking through a puddle. Or the feel of a spring breeze was the yellow aura in a Charles Burchfield landscape. By explaining the phenomenology of synaestheisa and explaining works of 
art that were created by synaesthetes, the students were able to access a new well of creativity. After my lecture, I encouraged the students to immediately take this framework of synaesthesia and apply it to the multiple sensory exercise. Based on the original images they selected, I asked them a series of questions: How does the image make you feel? Do you feel this sensation or emotion in a particular part of your body? What memories surfaced from looking at the images? If you could make a soundtrack based on your image, what would it sound like? What type of media best represents your image? I stressed that any type of media was acceptable for the assignment - drawing, painting, collage - as long as it expressed this cross-modal experience. They now felt that their assignments were to capture an ineffable, subjective sense of experience. The assignment has given a structure for exploration and transformation of their minds. The students continued working on this assignment for another week before a class critique.

\section{Measurable Results - How Did The Students Respond? What Types of Work Did They Produce?}

After introducing synaesthesia and various case studies surrounding it, I found that students' creativity was intensely heightened. It allowed the students to access other sensory experiences for inspiration. Along with the artist case studies and their own sensory perceptions, students started to experiment with various media to create art. Understanding the cross-modal experience of synaesthesia gave each student a greater conscious perception of their own experiences of the world around them.

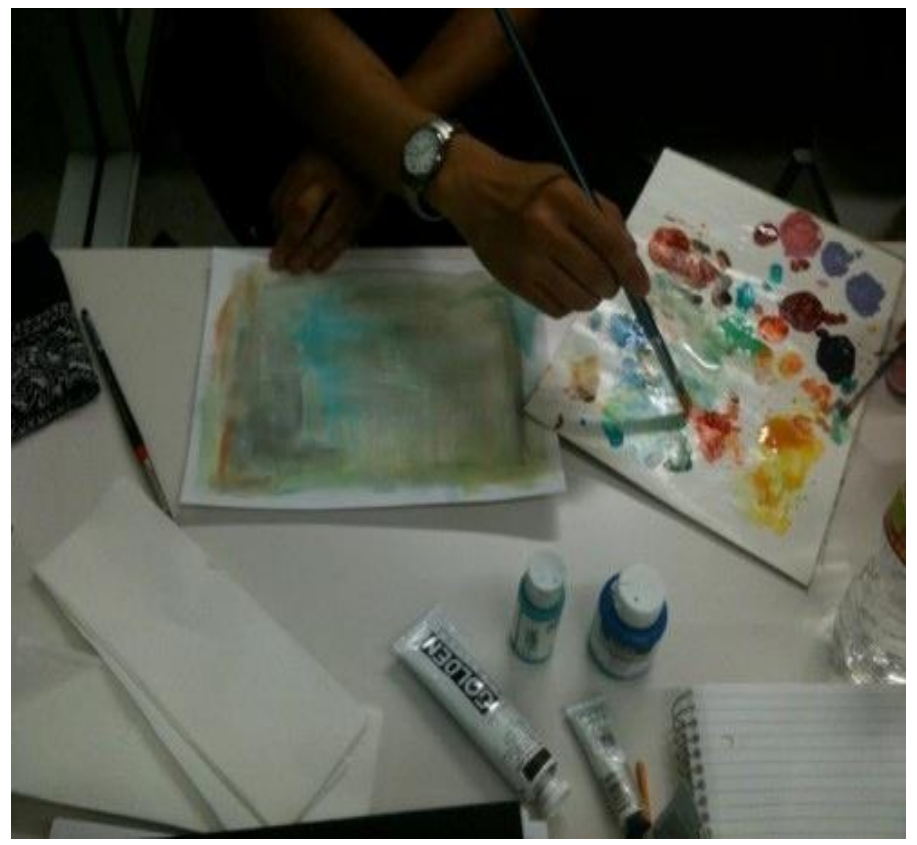


The critiques we held in the class meetings following the assignment were always interesting. Students, often timid to speak in front of groups, could easily talk for 10 minutes trying to explain the sensation of watching a sunset, and trying to capture that sensation on paper. Others felt complete and total freedom in creating nonrepresentational art. They were creating art that expressed an experience, emotion, or sensory perception and not merely replicating the likeness of an object. For many, this was the first time they felt inspired to create this type of art. They felt enabled to experiment with various media, including: watercolour, gauche, acrylic, markers, and pencils. The most popular, consistent media used in this assignment was paint.

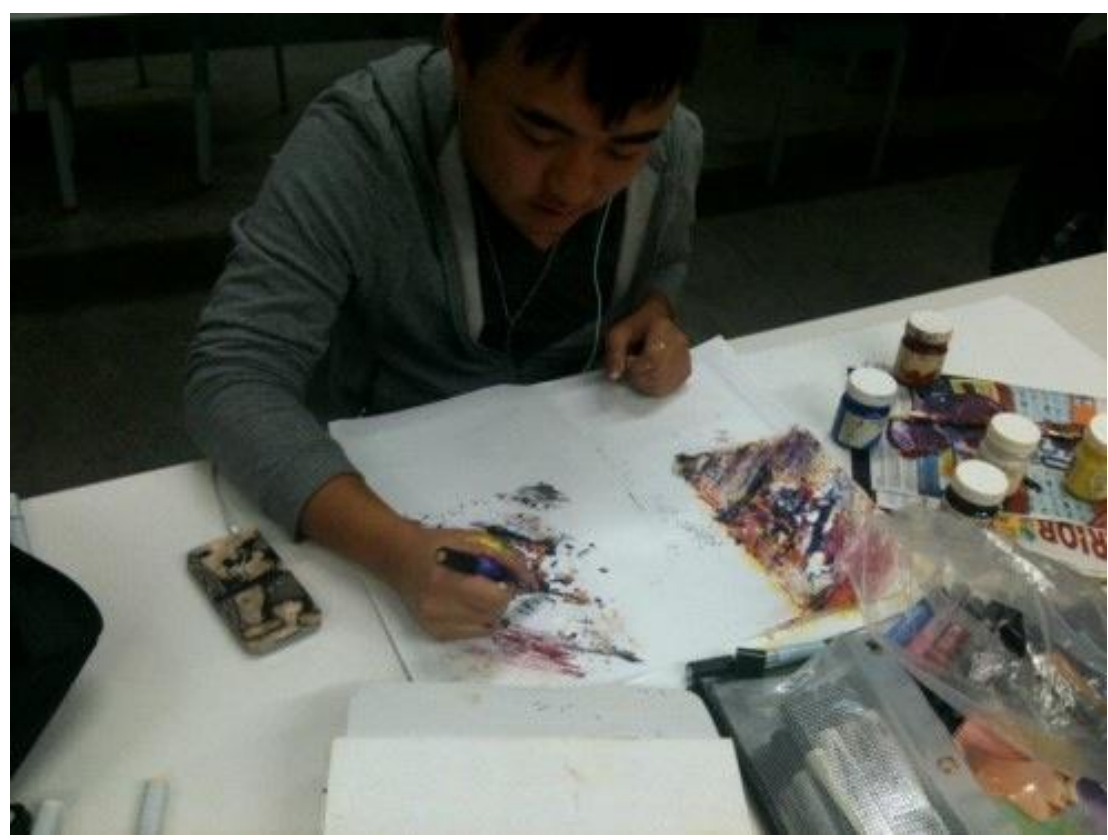

The artwork was compelling, and evocative of other sensory perceptions. During the critiques, the presenters would beam with pride as the audience would shout out what sense the artwork was communicating. It became a rather fun guessing game, which furthered into a dialog of subjective and objective experiencing of the external world. As Boden suggested, introducing synaesthesia as a structure allowed new thoughts and mental processes to develop in the students' minds.

\section{How Teaching this Methodology has Impacted my Own Creative Process}

I have been a painter for years, and noticed an impact on my work after exploring synaesthesia as a gateway to creativity. First, I moved more toward abstraction. I started experimenting with various types of paints and carrier oils. Using unfamiliar media allowed me to let go of the expectation of what I should paint. Every time I approached my canvas 
became a big experiment. I learned to allocate time to paint, and experiment with the media to let the imagery emerge on its own. As a painter, it is difficult to express to another person that moment when you know the work is finished. However, I started to realize when my paintings where finished when they evoked a certain sensory perception or memory. ${ }^{1}$

For example, the image below is a detail of a recent painting I made. It is a cross-modal representation of raindrops dripping on a puddle. The dark circles are the visual phenomenon of the rain falling on the puddle, while the silver paint is the soft sound of the water making contact with the ground. The painting thus merges the visual field with the aural and perceptual fields of experience.

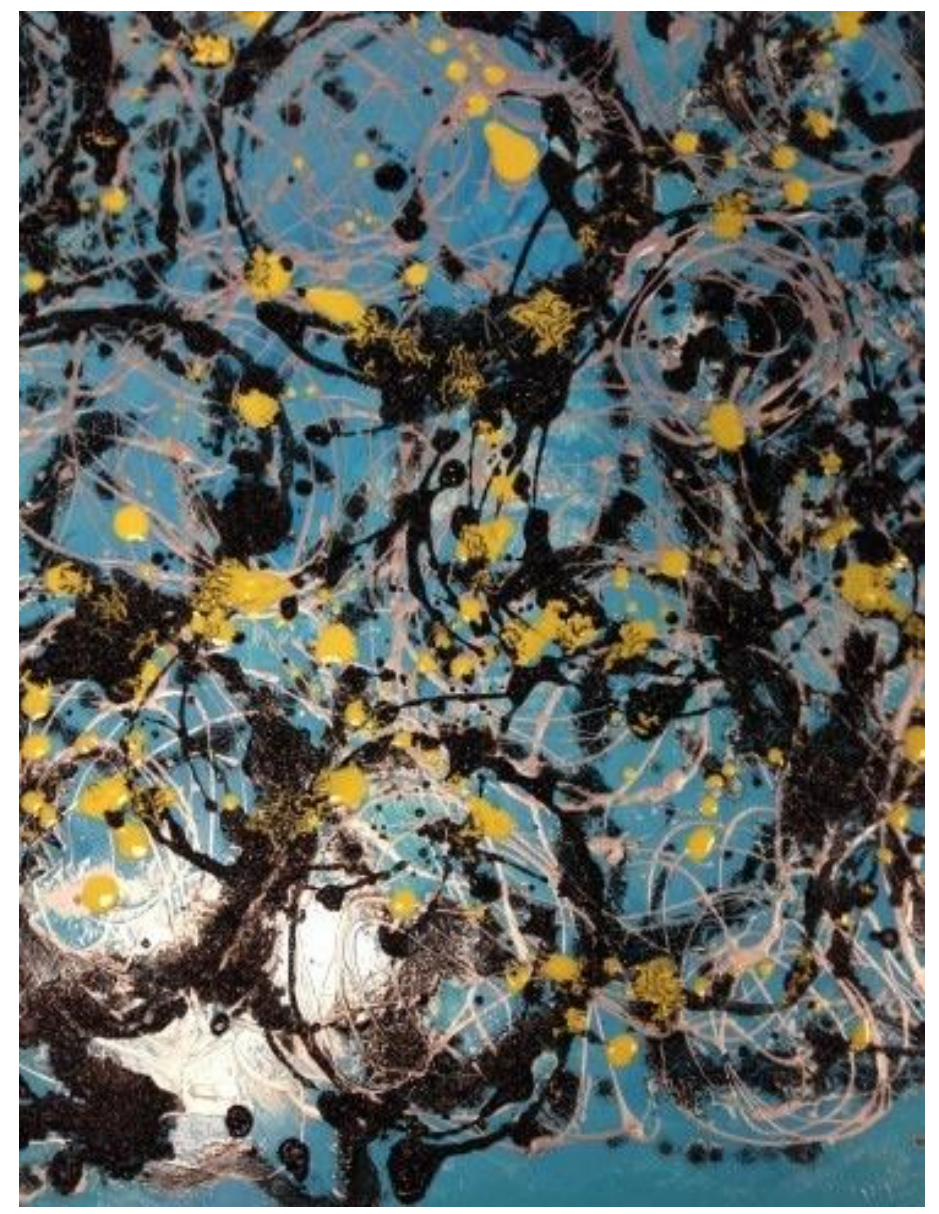

Through my own artistic practice and my teaching, I have shown that understanding the phenomenology of synaesthesia can lead to a heightened sense of creativity. It expands the awareness of the individual's sensory perception of the world and it becomes easier to experience the external world holistically. Synaesthesia illustrates a new

\footnotetext{
${ }^{1}$ For more on my personal reflections of creating art, please visit: http://monicadmurgia.com/category/ineffable/
} 
structure for making arbitrary links between unrelated visceral stimuli. It also allows the non-synaesthetic artist to abandon the traditional narrow scope of what art should be. Creating art thus becomes a spontaneous interpretation of the senses to illustrate the subjective experience of life.

\section{References}

Boden, Margaret A. (2004) The Creative Mind: Myths and Mechanisms. (New York: Routledge)

De Young, R. (2014). Using the Stroop effect to test our capacity to direct attention: A tool for navigating urgent transitions. Retrieved from http://www.snre.umich.edu/eplab/demos/st0/stroopdesc.html

Ramachandran, V.S. and Edward M. Hubbard (2003) 'Hearing Colours, Tasting Shapes,' The Scientific American, May 2003.

To cite this article:

Murgia, M. (2015). Teaching Synaesthesia as a Gateway to Creativity. Exchanges: The Warwick Research Journal, 2(2), 305-313. Retrieved from: http://exchanges.warwick.ac.uk/index.php/exchanges/article/view/51 